\title{
Factors Associated with Under Utilization of Intermittent Preventive Treatment Using Sulfadoxine - Pyrimethamine among Pregnant Women Attending Antenatal Clinic in Gusau District of Gusau Local Government Area, Zamfara State of Nigeria
}

\section{Bello Liman*}

Department of Public Health, National Open University of Nigeria, Nigeria

*Corresponding Author: Bello Liman, Department of Public Health, National Open University of Nigeria, Nigeria.

Received: September 25, 2019; Published: October 10, 2019

DOI: 10.31080/ASNH.2019.03.0485

\begin{abstract}
Objective: The aim of the study is to find out the strategies to bridge the gaps causing the low utilization of Sulfadoxine - Pyrimethamine among pregnant women attending an antenatal clinic.

Methods: Mixed methods were used which comprised of quantitative cross sectional study and qualitative focus group discussions. Four hundred and sixty - one (461) pregnant women were interviewed by using a pretested questionnaire and a focus group discussion guide in seven randomly selected health facilities. Secondly, heads of antenatal clinics of the selected health facilities were interviewed with the support of pretested questionnaire and observation checklist.

Results: In this study, the health system factors identified as responsible for low utilization of SP among the interviewed pregnant women include poor attitudes of health workers, lack of IPTp training, distance of health facility, lack of IPTp supervision and also lack of implementing DOT. On the other hands, the patient factors identified are followed, irregular ANC visits, poor acceptance of SP, lack of partner approval and late registration of the ANC visits.

Conclusion: The factors identified as responsible for low utilization of SP among the pregnant women attending an antenatal clinic in Gusau district, required serious attention from all levels (federal, state, LGA, health facility and community) in order to promote the uptake of SP within the pregnant women, so as to minimize the menace of malaria in pregnancy and infant and maternal mortality in order to achieve the MDG 4 and MDG 5 goals.
\end{abstract}

Keywords: Pregnant Women; ANC Visit; SP; DOT; IPTp; Nigeria

\section{Introduction}

Malaria parasite in pregnancy causes serious problems like jeopardizing the health of pregnant women, compromising the health of the foetus and increasing the likelihood of adverse pregnancy outcomes such as stillbirth, spontaneous abortion and low birth weight [1]. Intermittent Preventive Treatment of Malaria in Pregnancy (IPTp) is one of the strategies where pregnant women in malaria - endemic countries receive complete doses of Sulfadoxine - Pyrimethamine (SP), whether or not have the symptom of malaria. As a protective measure, in 2005, the Federal Government of Nigeria has approved the prevention of malaria in pregnancy intervention as a component of focused antenatal care in order to reduce the burden of malaria in the country [2]. The key interventions available in the public health facilities at the ANC for the prevention of malaria in pregnancy include administration of Sulfadoxine - Pyrimethamine for intermittent preventive treatment through directly observed therapy, distribution of long lasting insecticidal nets and appropriate case management [2]. Fansidar, Amalar and Maloxine are some of the most common brand names of Sulfadoxine - Pyrimethamine available in Nigeria [1]. 
Factors Associated with Under Utilization of Intermittent Preventive Treatment Using Sulfadoxine - Pyrimethamine among Pregnant Women Attending Antenatal Clinic in Gusau District of Gusau Local Government Area, Zamfara State of Nigeria

According to national protocol, the pregnant women are given Sulfadoxine Pyrimethamine free of charge through ANC at public health facilities and non -governmental organization facilities [1]. As far SMOH, 2015, the state has a projected population of $4,328,270$ and based on this figure, the state expected 216,414 of pregnant women. These numbers of pregnant women are expected to at least receive two doses of SP during ANC visits to health facilities in the state. But the pregnant women who received IPT at least one dose were $9.7 \%$ and those who received 2 doses were $6.6 \%$ respectively [1]. Therefore, based on the above information, if we failed to initiate the possible ways of tackling this problem, the main objective of reducing maternal, infant and neonatal mortality in the state may likely not be significantly achieved. So, for this purpose, the researcher decided to carry out an investigation on the issue for possible solutions.

The public health burden of malaria was due to combination factors, such as increasing resistance of malarial parasites to chemotherapy and of that of Anopheles mosquito vector to insecticides.

The maternal illness and low birth weight in African region where malaria transmission is either high or medium, the use of Sulfadoxine Pyrimethamine (SP) as IPTp has been recommended by World health organization in the year of 2004. The intermittent preventive treatment in pregnancy (IPTp) has been recommended for pregnant women with malaria due to lack of effective and safe vaccine for that purpose (Mohammad, 2013 cited WHO, 2010). The main aim is to ensure that pregnant women with malaria symptoms or who are not attending the antenatal clinic have received the require amount of at least two doses of SP at second and third trimesters.

Pregnant mothers residing in malaria endemic regions are to use insecticide - treated bed nets and IPTp - SP (intermittent presumptive treatment in pregnancy with at least 2 doses of Sulfadoxine - Pyrimethamine), study's findings indicated poor uptake of both preventive measures among pregnant women. A current survey on postpartum women in rural Uganda where $88 \%$ of pregnant women attended more than one prenatal visit, only $31 \%$ of women slept under bed nets during pregnancy and 36\% had received 2 doses of IPTp - SP (Mohammad, 2013 cited Kiwuwa and
Mufebenga, 2008). This interprets that access to and utilization of ante partum care increase, but redouble efforts need to improve the administration of IPTp - SP and education for the use of insecticide - treated bed net.

The recent recommended focused ANC package incorporates a range of interventions (Mohammad, 2013 cited WHO, 2010). Antenatal care is considered as a vital meeting point between the health care providers and pregnant women and also a golden opportunity for health education, detection of pregnancy complications and birth plan for health facility delivery (Mohammad, 2013 cited Abouzahr and Ward law, 2003).

It was estimated that in sub - Saharan Africa one out of four women demonstrates evidence of placental infection during delivery and have pregnant women's malaria infection that not detected and also not treated [3]. In 2004, the World Health Organization estimated that malaria induced low birth weight and responsible for about 360,000 newborn deaths every year in malaria endemic area of Africa. This figure is estimated to step down to 100,000 in 2007 [3]. Generally, in malaria endemic areas of Africa, malaria in pregnancy as estimated was accounted for $11.4 \%$ of neonatal, and $5.7 \%$ of infant deaths $[3,4]$.

The World Health Organization reported that 35 in 45 of the sub - Saharan African countries, warmly introduced IPTp -SP into their national policy (Path, 2014 cited Onoka., et al. 2012). However, having IPTp - SP strategies in the national policy do not make it effective until properly implemented and adhered to [3].

The pregnant women are to receive three or more doses of SP before deliveries, recommended by the World Health Organization. In line with national policy and guidelines, SP is given at ANC visits by skilled health care providers through directly observed therapy [3]. Therefore, pregnant women to receive all doses required need to attend all the ANC visits as scheduled. To get this done, health facilities are to have enough supply of SP and portable drinking water to administer SP under DOT should be on the ground. Lack of these factors is barriers to women receiving the recommended dosage. Recent estimates stated that only $24.5 \%$ of pregnant women received at least two doses of SP before delivery [3]. 
A cross sub - Saharan Africa, ANC attendance differs as follows, $71 \%$ of pregnant mothers attend formal ANC at least once, and 44\% attend ANC four or more times (Mohammad, 2013 cited Kinney, 2010). To encourage pregnant women complete the required ANC visits, WHO recommends women to initiate an ANC visit during the first trimester of pregnancy (Mohammad, 2013 cited WHO, 2007). Comprehensive analysis of DHS data in 1990s, stated that below $30 \%$ of pregnant women met the target (Mohammad, 2013 cited WHO, 2007). Demographic and Health Survey findings showed that only $11 \%$ of pregnant mothers started ANC in the first trimester in Ethiopia, 2011, 16\% in Nigeria, 2008, 47\% in Congo Brazzaville, 2005 and 55\% in Ghana, 2008. However, in sub - Saharan countries for the last 10 to 20 years, the trend proportion of women who had at least four ANC visits varies accordingly (Mohammad, 2013 cited Wang, 2011).

In Ghana, malaria in pregnant women accounts for $13.8 \%$ of out - patients' attendance, $10.6 \%$ of admissions and $9.4 \%$ of maternal death [5].

Ghana has approved the use of WHO's recommendation in 2005, which stated that the pregnant women should be given at least two doses of intermittent preventive treatment (IPT) using the Sulfadoxine - Pyrimethamine (SP) after quickening at monthly intervals [5]. The world malaria report of 2008 indicated that Ghana had an estimated 7.2 million cases of malaria in 2006 (WHO, 2008).

In Zambia, malaria in pregnancy is a major health problem faced by women and infants. As part of the effort of the Zambia Government to tackle the problem, medical health policy reform passed in 1991.Restructuring of primary health care is an important component noted in the reform [6].

Malaria infection in pregnant women is mostly asymptomatic, means pregnant women with malaria are not feeling ill. Similarly, their blood tests may show negative in terms of malaria parasites [6].

The pregnant women morbidity due to malaria is anaemia, fever, hypoglycaemia, cerebral malaria, pulmonary oedema and puerperal sepsis. Severe malaria and hemorrhage may lead to mortality. In case of newborn, issues of low birth weight, prematurity, intrauterine Growth Retardation (IUGR), fever and mortality may all occurred [6].

Malaria is still the major cause of morbidity and mortality in $\mathrm{Ni}$ geria. It is directly related to poverty, less productivity and reduced school attendance. The mosquito borne illness causes over 100 million clinical cases annually. In Nigeria, malaria accounts for 60 percent outpatient attendance, 30 percent of hospital admissions and 25 percent deaths for children under 5 years as well as 11 percent of maternal mortality [7]. Pregnant women, especially those in first and second pregnancy and children under 5 years are the most vulnerable groups.

In 2004, Nigerian Government approved the prevention of malaria in pregnancy intervention as a component of Focused Antenatal Care in order to down the burden of malaria in the country. In all the public facilities the malaria preventive services have been given free of charge, but still the coverage remained low due to ongoing poor antenatal attendance, particularly in the northern part of the country where ANC attendance recorded below 30\% [1]. Focused Antenatal Care is the most effective, practical platform for the delivery of the interventions. Administration of Sulfadoxine - Pyrimethamine under directly observed therapy/treatment for intermittent preventive treatment, distribution of long lasting insecticidal nets and appropriate case management via prompt diagnosis as well as effective treatment with recommended medicines.

In second and third trimesters of pregnancy, Sulphonamides and Pyrimethamine are safe, but some concerns rose about sulpha drugs that may be associated with jaundice when administered to pre- term neonates. In studies carried out on IPT where SP administered to mothers, this problem has not been observed [2]. Similarly, studies conducted which examining the risk to the foetus in utero exposed to SP combinations revealed that no any increased risk in spontaneous abortions or congenital defects (FMoH, 2015 cited Hernandez., et al. 2000, Newman., et al. 2001).

Sulfadoxine (N - \{5, 6-dimethoxy - 4-pyrimidinyl $\}$ sulphanilamide) also known as sulphonamide has a long half - life (7 to 9 days). The sulfadoxine is used in combination with Pyrimethamine (500mg of sulfadoxine and $25 \mathrm{mg}$ of Pyrimethamine) for prophylaxis and treatment of malaria due to Plasmodium falciparum (Patrick, 2010 cited William and Petri, 2001). Sulfadoxine has structural

Citation: Bello Liman. "Factors Associated with Under Utilization of Intermittent Preventive Treatment Using Sulfadoxine - Pyrimethamine among Pregnant Women Attending Antenatal Clinic in Gusau District of Gusau Local Government Area, Zamfara State of Nigeria". Acta Scientific Nutritional Health 3.11 (2019): 36-52. 
analogs of $\mathrm{p}$ - amino benzoic acid (PABA) which inhibits dihydrofolic acid synthesis by inhibiting an enzyme called dihydropteroate synthetase, which has a vital role in the conversion of PABA to folic acid. Pyrimethamine is an antagonist to folic acid, with similar mechanism of action with trimethoprim. Pyrimethamine inhibits the reduction of dihydrofolic acid to tetrahydrofolic acid. Pyrimethamine interferes with tetrahydrofolic acid synthesis in malaria parasites.

Sulfadoxine and Pyrimethamine combination results in a synergistic action against susceptible plasmodia. Sulfadoxine and Pyrimethamine are blood schizonticidal agents and are active against the sexual erythrocytic forms of susceptible plasmodia (www. malaria - ipca.com) (Patrick, 2010).

As important public health problem in Africa, malaria contributes significantly to harmful effect outcome of pregnancy (WHO, 2013). Uganda recorded as third in the world in terms of fertility rate against malaria in pregnancy (Accessed, 2013). In Africa, the key component of WHO's strategy to control the adverse impact of malaria on pregnancies is named as intermittent preventive treatment of malaria in pregnancy (IPTp) with Sulphadoxine - Pyrimethamine (SP) (WHO, 2004). Despite the fact that malaria - endemic countries are adopting IPTp as policy, it has been noted that the debate is globally on progress concerning the issue of whether Sulfadoxine - Pyrimethamine is currently the most appropriate treatment (Chico and Chandra Mohan, 2011, Valley., et al. 2007).

\section{Materials and Methods}

\section{Conceptual frame work}

The conceptual framework provides significant information on those factors that may likely cause the low utilization of intermittent preventive treatment in pregnancy using Sulfadoxine Pyrimethamine among pregnant women in the Gusau district and the ways these factors are linked to each other as shown below. So, this research work study was carried out within this framework. In line of this, the information generated from the socio demographic factors may likely influence the health care seeking behaviour of the respondents and may likely affect the utilization of Sulfadoxine Pyrimethamine.

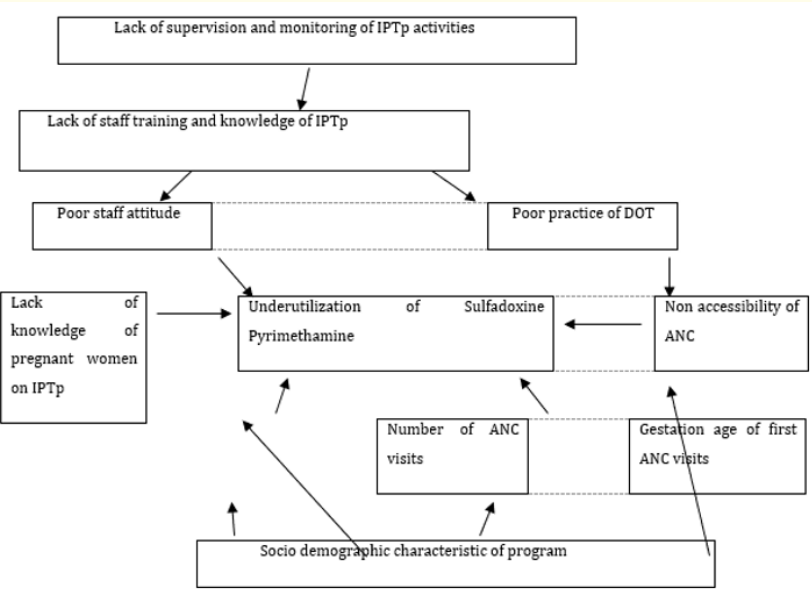

Figure a

\section{Study design}

In this study, mixed methods were used which comprised a quantitative cross - sectional study and qualitative focus group discussions respectively.

\section{Study populations}

The study population comprised of Women of reproductive age group (WRAG) in second and third trimesters of pregnancy, attending antenatal clinics in selected health facilities; healthcare workers and the health facilities in the study area.

\section{Eligibility/Exclusion criteria}

Women of reproductive age group who have been medically exempted from taking the drug based on history of adverse reactions were not eligible for the study.

\section{Sampling techniques/Study procedure}

Four hundred and sixty - one (461) of pregnant women were interviewed by using a pretested questionnaire in all the seven randomly selected health facilities. The health facilities were stratified by level of care as follows: two tertiary, two secondary and ten primaries. Half of the number of facilities was selected by simply random sampling through balloting and www.random.org/integer accessed on 21/09/2014. Federal Medical Centre was selected at the tertiary level, at the secondary level of care, Farida General Hos- 
Factors Associated with Under Utilization of Intermittent Preventive Treatment Using Sulfadoxine - Pyrimethamine among Pregnant Women Attending Antenatal Clinic in Gusau District of Gusau Local Government Area, Zamfara State of Nigeria

pital was selected and the following health facilities were selected for primary level of care: Sabon Gari PHC, Shagari PHC, Dr. Karima PHC, PHC Kwata and Gada - Biyu Clinic. Therefore, the number of subjects selected in each health facility is proportional allocation of samples in a stratified sampling, which will be by formula:

Number of subjects in the health facility

Total number of subjects in all the

X Total sample size

health facilities

\begin{tabular}{|l|c|c|}
\hline Name of Health facility & Type of Health facility & $\begin{array}{c}\text { Sample } \\
\text { size }\end{array}$ \\
\hline Federal Medical Centre & Tertiary Health facility & 134 \\
\hline Farida General Hospital & $\begin{array}{c}\text { Secondary Health } \\
\text { facility }\end{array}$ & 117 \\
\hline Shagari PHC & Primary Health facility & 45 \\
\hline Dr. Karima WCWC & Primary Health facility & 109 \\
\hline Sabon Gari PHC & Primary Health facility & 13 \\
\hline Gada - Biyu Clinic & Primary Health facility & 18 \\
\hline PHC Kwata & Primary Health facility & 25 \\
\hline
\end{tabular}

Table 1: Proportional Allocation of Sample size.

Sample size

Sample size of pregnant women

The optimum number of pregnant women of the study was calculated by using the standard formula as follows:

The $\mathrm{Z}$ - test formula was used to determine the minimum sample size in the study as follows:

$\mathrm{N}=\mathrm{Z} 2 \mathrm{pq} / \mathrm{d} 2$

Where $\mathrm{N}=$ the desired sample size

$\mathrm{Z}=$ the standard normal deviate, usually set at 1.96 which corresponds to $95 \%$ confidence interval.

$\mathrm{p}=50 \%$ prevalence of use of the SP in pregnant women in the previous study (MOH, 2013).

$\mathrm{q}=1-\mathrm{p}$

$\mathrm{d}=$ Degree of accuracy desired $=0.05$

$\mathrm{N}=(1.96) 2 \times 0.5 \times 0.5 /(0.05) 2$

$\mathrm{N}=3.8416 \times 0.5 \times 0.5 / 0.0025$
$\mathrm{N}=384.16$, approximately $=384$

Add 20\% of 384 for non-response: 77

$\mathrm{N}=461$

Size Sample of health care providers

In each of the selected seven health facilities, antenatal staff was interviewed by using a pretested questionnaire called a questionnaire for antenatal clinic health care providers. As the number of respondents required was very small; therefore, the issue of calculating the sample size of health care providers did not arise.

Reliability test of instruments by using Cronbach's and analysis methods

The data collection instruments were generally validated by a team of eleven consultants at the community health department, Usmanu Danfodiyo University Teaching Hospital Sokoto, Sokoto state of Nigeria. Each question of the questionnaires was rated one after the other by each consultant on excel sheet and then later compiled the rated data before copied and pasted on the file of SPSS statistics version 20 software for further analysis. After data analysed, the cronbach's alpha of each questionnaire was obtained as follows:

\begin{tabular}{|l|c|}
\hline Item & Cronbach's Alpha \\
\hline Pregnant women questionnaire & 0.926 \\
\hline Health care providers questionnaire & 0.902 \\
\hline Focus group guide discussion & 0.803 \\
\hline Observation checklist & 0.787 \\
\hline
\end{tabular}

Table 2: Data collection tools Validation results.

Reliability of Pregnant women questionnaire

The reliability process of the pregnant women questionnaire was carried out at the community health department, Usmanu Danfodiyo University, Sokoto, Sokoto state of Nigeria by a team of eleven consultants. Each question of the questionnaire was rated by the consultants separately on excel sheet and then later compiled the rated data before copied and pasted on SPSS file for further analysis. At the end of the analysis the cronbach's alpha was released as 0.926 .

Reliability of health care provider's questionnaire

The health care providers' questionnaire was also passed through the reliability process held at the same venue with that of

Citation: Bello Liman. "Factors Associated with Under Utilization of Intermittent Preventive Treatment Using Sulfadoxine - Pyrimethamine among Pregnant Women Attending Antenatal Clinic in Gusau District of Gusau Local Government Area, Zamfara State of Nigeria". Acta Scientific Nutritional Health 3.11 (2019): 36-52. 
pregnant women questionnaire by the same team of eleven consultants. Each consultant rated the questions of the questionnaire one after the other and then the rated data were compiled before it was copied and pasted to SPSS file for further analysis. The cronbach's alpha for the health care providers questionnaire was determined as 0.902 .

\section{Reliability of Focus group discussion guide}

The focus group discussion guide was not left behind in terms of reliability test; therefore the instrument was tested as did to previous questionnaires, held at the community health department, Usmanu Danfodiyo University, Sokoto, Sokoto State of Nigeria by the same team of consultants and through the same process. The analysis done through SPSS Statistics version 20 Software revealed the cronbach's alpha of the focus group discussion guide as 0.803 .

\section{Reliability of Observation checklist}

The observation checklist as other previous tested questionnaires was also passed through the reliability process carried out by the same team of consultants. The further analysis done through SPSS Statistics version 20 Software revealed the cronbach's alpha of the observation checklist as 0.787 .

\section{Validation of instruments}

The data collection instruments were assessed by public health practitioners with a view to ensure whether the instruments are capable of measuring what are designed to measure.

\section{Data collection}

\section{Interviews of pregnant women}

A pretested questionnaire was used to generate data from the pregnant women who came to a health facility for ANC visits in all the seven selected health facilities. The pregnant women were interviewed with the support of pretested questionnaire. The section A of the questionnaire was focused on social demographic factors, section B was about the distance, transportation and cost to a health facility, section $C$ was on utilization of maternal health care, section D was on perception of quality of health services, section E was on knowledge of IPTp and section F focused on the use of IPTp. Attached in the appendix 1 and 2 were the English version questionnaire and Hausa version questionnaire respectively.

\section{Focus group discussions}

The focus group discussions were an additional phenomenon used to generate data from pregnant women who attended ANC by using a guide called a focus group discussion guide. This focus group discussion guide was designed to focus on behaviour, attitude and perception of pregnant women on utilization of SP, which was the main reason questions on behaviour, attitude and perception were initiated so as to start the discussions in the right direction. In all the seven selected health facilities, focus group discussions were conducted and in each focus group discussion ten pregnant women were in attendance.

\section{Interviews of health care providers}

In all the selected health facilities, health care providers working in the antenatal clinics were interviewed by using a pretested questionnaire known as questionnaire for health care providers. The section A of the questionnaire was in general information, section B was on knowledge of IPTp and section $\mathrm{C}$ was on the practice of IPTp.

\section{Observation checklist}

The pretested observation checklist was used in collecting data on what was available and practicing for intermittent preventive treatment in pregnancy in all selected health facilities. Health care providers were interviewed with support of observation checklist.

Data analysis

For data analysis, the SPSS Statistics version 20 software was used to obtain the correlation coefficient for testing or determining the association between the variables and SP uptake.

\section{Study limitation}

The study was focused only on pregnant women who attended the antenatal clinic at the seven randomly selected health facilities in the Gusau district of Gusau Local Government Area, Zamfara State of Nigeria.

\section{Ethical considerations}

The Zamfara State Operational Research Advisory Committee issued ethical clearance and approval before the commencement of the study. Similarly, the Federal Medical Centre, Gusau also issued ethical approval before the collection of data commenced. Participants were informed of the nature of the study, procedures, and objectives respectively. Likewise, they were given assurance of their privacy and confidentiality. In addition, the participants were aware that they have the right to withdraw from the research at any time the need arise. 


\section{Results and Discussion}

\begin{tabular}{|c|c|c|}
\hline Age status & $\begin{array}{c}\text { Frequency } \\
(\mathrm{N}=461)\end{array}$ & $\begin{array}{c}\text { Percentage } \\
(\mathrm{n} / 461) \times 100\end{array}$ \\
\hline$<20$ & 59 & $12.7 \%$ \\
\hline $20-30$ & 327 & $71.0 \%$ \\
\hline$>30$ & 75 & $16.3 \%$ \\
\hline Marital status & $\begin{array}{l}\text { Frequency } \\
(\mathrm{N}=461)\end{array}$ & $\begin{array}{c}\text { Percentage } \\
(\mathrm{n} / 461) \times 100\end{array}$ \\
\hline Number of married women & 448 & $97.2 \%$ \\
\hline Number of divorce women & 11 & $2.4 \%$ \\
\hline Number of widow women & 2 & $0.4 \%$ \\
\hline Occupation & $\begin{array}{l}\text { Frequency } \\
(\mathrm{N}=461)\end{array}$ & $\begin{array}{c}\text { Percentage } \\
(\mathrm{n} / 461) \times 100\end{array}$ \\
\hline Number of unemployed & 344 & $74.6 \%$ \\
\hline Number of traders & 75 & $16.3 \%$ \\
\hline Number of civil servants & 42 & $9.1 \%$ \\
\hline Education status & $\begin{array}{l}\text { Frequency } \\
(\mathrm{N}=461)\end{array}$ & $\begin{array}{c}\text { Percentage } \\
(\mathrm{n} / 461) \times 100\end{array}$ \\
\hline $\begin{array}{l}\text { Number of pregnant women } \\
\text { who acquired Primary educa- } \\
\text { tion }\end{array}$ & 57 & $12.4 \%$ \\
\hline $\begin{array}{l}\text { Number of Pregnant women } \\
\text { who acquired Islamiya educa- } \\
\text { tion }\end{array}$ & 258 & $55.9 \%$ \\
\hline $\begin{array}{l}\text { Number of pregnant women } \\
\text { who acquired Secondary edu- } \\
\text { cation }\end{array}$ & 140 & $30.4 \%$ \\
\hline $\begin{array}{l}\text { Number of pregnant women } \\
\text { who acquired Tertiary educa- } \\
\text { tion }\end{array}$ & 6 & $1.3 \%$ \\
\hline Obstetric history status & $\begin{array}{l}\text { Frequency } \\
(\mathrm{N}=461)\end{array}$ & $\begin{array}{c}\text { Percentage } \\
(\mathrm{n} / 461) \times 100\end{array}$ \\
\hline $\begin{array}{l}\text { Gravidity: Number of pregnant } \\
\text { women with first pregnancy }\end{array}$ & 88 & $19.1 \%$ \\
\hline $\begin{array}{l}\text { Number of pregnant women } \\
\text { with second pregnancies }\end{array}$ & 138 & $29.9 \%$ \\
\hline $\begin{array}{l}\text { Number of pregnant women } \\
\text { with third and above pregnan- } \\
\text { cies }\end{array}$ & 235 & $51.0 \%$ \\
\hline Parity: $1-5$ & 387 & $83.9 \%$ \\
\hline$>5$ & 74 & $16.1 \%$ \\
\hline Number of living children & 1,450 & \\
\hline Number of death children & 27 & \\
\hline
\end{tabular}

Table 3: Socio - Demographic status.

\begin{tabular}{|c|c|c|}
\hline Variables & $\begin{array}{c}\text { Frequency } \\
(\mathrm{N}=461)\end{array}$ & $\begin{array}{c}\text { Percentage } \\
(n / 461) \times 100\end{array}$ \\
\hline $\begin{array}{l}\text { Number of pregnant } \\
\text { women maltreated during } \\
\text { ANC visits by health care } \\
\text { providers }\end{array}$ & 100 & $21.6 \%$ \\
\hline $\begin{array}{l}\text { Number of pregnant } \\
\text { women who were living } \\
\text { far away from the health } \\
\text { facility }\end{array}$ & 250 & $54.2 \%$ \\
\hline $\begin{array}{l}\text { Number of pregnant } \\
\text { women who complained } \\
\text { about the poor quality of } \\
\text { services }\end{array}$ & 10 & $2.2 \%$ \\
\hline \multicolumn{3}{|l|}{ Drug effects } \\
\hline Nausea & 25 & $5.4 \%$ \\
\hline Rashes & 11 & $2.3 \%$ \\
\hline Headache & 16 & $3.4 \%$ \\
\hline Vomiting & 20 & $4.3 \%$ \\
\hline Variables & $\begin{array}{c}\text { Frequency } \\
(\mathrm{N}=7)\end{array}$ & $\begin{array}{c}\text { Percentage }(\mathrm{n} / 7) \\
\text { x } 100\end{array}$ \\
\hline $\begin{array}{l}\text { Number of health care } \\
\text { providers trained on IPTp }\end{array}$ & 1 & $14.2 \%$ \\
\hline $\begin{array}{l}\text { Number of health care } \\
\text { providers supervised on } \\
\text { IPTp }\end{array}$ & 1 & $14.2 \%$ \\
\hline $\begin{array}{l}\text { Number of health facility } \\
\text { implemented DOT }\end{array}$ & 3 & $42.8 \%$ \\
\hline $\begin{array}{l}\text { Number of health facility } \\
\text { with equipment/facility } \\
\text { for conducting IPTp }\end{array}$ & 7 & $100 \%$ \\
\hline $\begin{array}{l}\text { Number of health facility } \\
\text { invited community living } \\
\text { around the catchment } \\
\text { areas when planning for } \\
\text { ANC session }\end{array}$ & 2 & $28.5 \%$ \\
\hline $\begin{array}{l}\text { Number of health facility } \\
\text { conducted at least two } \\
\text { ANC per week }\end{array}$ & 7 & $100 \%$ \\
\hline
\end{tabular}

Table 4: Health system factors. 
Factors Associated with Under Utilization of Intermittent Preventive Treatment Using Sulfadoxine - Pyrimethamine among Pregnant Women Attending Antenatal Clinic in Gusau District of Gusau Local Government Area, Zamfara State of Nigeria

\begin{tabular}{|l|c|c|c|}
\hline Variables & Frequency & $\begin{array}{c}\text { Percentage } \\
\text { (n/461) x } \\
\text { 100 }\end{array}$ & $\begin{array}{c}\text { Correlation } \\
\text { coefficient } \\
\text { (r) }\end{array}$ \\
\hline $\begin{array}{l}\text { Age status } \\
<20\end{array}$ & 59 & $12.7 \%$ & $\mathrm{r}=1$ \\
$20-30$ & 327 & $71.0 \%$ & \\
$>30$ & 75 & $16.3 \%$ & \\
\hline $\begin{array}{l}\text { Parity } \\
\text { 1-5 }\end{array}$ & 387 & $83.9 \%$ & $\mathrm{r}=1$ \\
$>5$ & 74 & $16.1 \%$ & $\mathrm{r}=1$ \\
\hline $\begin{array}{l}\text { Marital Status } \\
\text { Married }\end{array}$ & 448 & $97.2 \%$ & \\
$\begin{array}{l}\text { Divorce } \\
\text { Widow }\end{array}$ & 11 & $2.4 \%$ & \\
\hline $\begin{array}{l}\text { Education status } \\
\text { (N) }\end{array}$ & 258 & $55.9 \%$ & \\
$\begin{array}{l}\text { Number of preg- } \\
\text { nant women who } \\
\text { acquired primary } \\
\text { education }\end{array}$ & 57 & $12.4 \%$ & \\
$\begin{array}{l}\text { Number of preg- } \\
\text { nant women who } \\
\text { acquired Islamiya } \\
\text { education }\end{array}$ & & & \\
$\begin{array}{l}\text { Number of preg- } \\
\text { nant women who } \\
\text { acquired secondary } \\
\text { education }\end{array}$ & 140 & $30.4 \%$ & \\
\hline
\end{tabular}

Table 5: Socio -Demographic Characteristics Association with SP Administration (patient factors).

\begin{tabular}{|l|c|c|}
\hline Variables & $\begin{array}{c}\text { Frequency } \\
\text { (N = 461) }\end{array}$ & $\begin{array}{c}\text { Percentage } \\
\text { (n/461) x 100 }\end{array}$ \\
\hline $\begin{array}{l}\text { Number of pregnant women who } \\
\text { knew how to protect themselves } \\
\text { against malaria infection during } \\
\text { pregnancy }\end{array}$ & 310 & $67.2 \%$ \\
\hline $\begin{array}{l}\text { Number of pregnant women who } \\
\text { knew when to start taking SP } \\
\text { during pregnancy }\end{array}$ & 263 & $57 \%$ \\
\hline $\begin{array}{l}\text { Number of pregnant women who } \\
\text { knew how to use SP for the pre- } \\
\text { vention of malaria in pregnancy }\end{array}$ & 101 & $21.9 \%$ \\
\hline $\begin{array}{l}\text { Number of pregnant women who } \\
\text { knew when to stop taking SP }\end{array}$ & 300 & $65 \%$ \\
\hline $\begin{array}{l}\text { Number of pregnant women who } \\
\text { were aware with the side effects } \\
\text { of SP }\end{array}$ & 72 & $15.6 \%$ \\
\hline $\begin{array}{l}\text { Number of pregnant women } \\
\text { who knew the required amount } \\
\text { of SP tablets at four months of } \\
\text { pregnancy }\end{array}$ & 438 & $95 \%$ \\
\hline $\begin{array}{l}\text { Number of pregnant women who } \\
\text { knew the effects of malaria to } \\
\text { mother, baby or both of them }\end{array}$ & 204 & $94.2 \%$ \\
\hline $\begin{array}{l}\text { Number of pregnant women who } \\
\text { got awareness about SP through } \\
\text { health education talk at the } \\
\text { health facility during ANC visits }\end{array}$ & 446 & \\
\hline
\end{tabular}

Table 6: Pregnant women's knowledge on SP.

\begin{tabular}{|l|c|c|}
\hline Variables & $\begin{array}{c}\text { Frequency } \\
\text { (N = 7) }\end{array}$ & $\begin{array}{c}\text { Percentage } \\
\text { (n/7) x 100 }\end{array}$ \\
\hline $\begin{array}{l}\text { Number of health facility that did } \\
\text { not experienced stock out of Sulfa- } \\
\text { doxine Pyrimethamine for the last } \\
\text { three months }\end{array}$ & 7 & $100 \%$ \\
\hline $\begin{array}{l}\text { Number of health facility that did } \\
\text { not experienced shortages of Sulfa- } \\
\text { doxine Pyrimethamine for the last } \\
\text { three months }\end{array}$ & 7 & $100 \%$ \\
\hline $\begin{array}{l}\text { Number of health facility that re- } \\
\text { ceived the allocation of Sulfadoxine } \\
\text { Pyrimethamine quarterly }\end{array}$ & 7 & $100 \%$ \\
\hline
\end{tabular}

Table 7: Availability of SP in Primary, Secondary and Tertiary health facilities. 


\begin{tabular}{|c|c|c|}
\hline Variables & $\begin{array}{c}\text { Frequency } \\
(\mathrm{N}=7)\end{array}$ & $\begin{array}{l}\text { Percentage } \\
(\mathrm{n} / 7) \times 100\end{array}$ \\
\hline $\begin{array}{l}\text { Number of health care providers } \\
\text { who knew what IPT is all about }\end{array}$ & 7 & $100 \%$ \\
\hline $\begin{array}{l}\text { Number of health care providers } \\
\text { who were aware that Fansidar } \\
\text { was recommended as the first } \\
\text { line for pregnant women in } \\
\text { Nigeria. }\end{array}$ & 5 & $71.4 \%$ \\
\hline $\begin{array}{l}\text { Number of health care provid- } \\
\text { ers who knew that a health } \\
\text { facility with infrastructures to } \\
\text { determine gestational age can } \\
\text { start IPTp after quickening or } 13 \\
\text { weeks of pregnancy }\end{array}$ & 5 & $71.4 \%$ \\
\hline $\begin{array}{l}\text { Number of health care providers } \\
\text { who were aware that Directly } \\
\text { Observed Treatment (DOT) } \\
\text { strategy simply means the } \\
\text { administration of anti-malarial } \\
\text { medicine under the supervision } \\
\text { of skilled health care provider. }\end{array}$ & 7 & $100 \%$ \\
\hline $\begin{array}{l}\text { Number of health care providers } \\
\text { who were aware that vomiting, } \\
\text { headache, rashes and nausea are } \\
\text { the side - effects of SP }\end{array}$ & 7 & $100 \%$ \\
\hline $\begin{array}{l}\text { Number of health care providers } \\
\text { who agreed that HIV pregnant } \\
\text { women placed on cotrimoxa- } \\
\text { zole chemoprophylaxis are not } \\
\text { eligible to swallow SP }\end{array}$ & 5 & $71.4 \%$ \\
\hline $\begin{array}{l}\text { Number of health care provid- } \\
\text { ers who agreed that pregnant } \\
\text { women allergic to sulpha drugs } \\
\text { are not eligible to administer SP }\end{array}$ & 5 & $71.4 \%$ \\
\hline
\end{tabular}

Table 8: Health care provider's knowledge on IPTp.

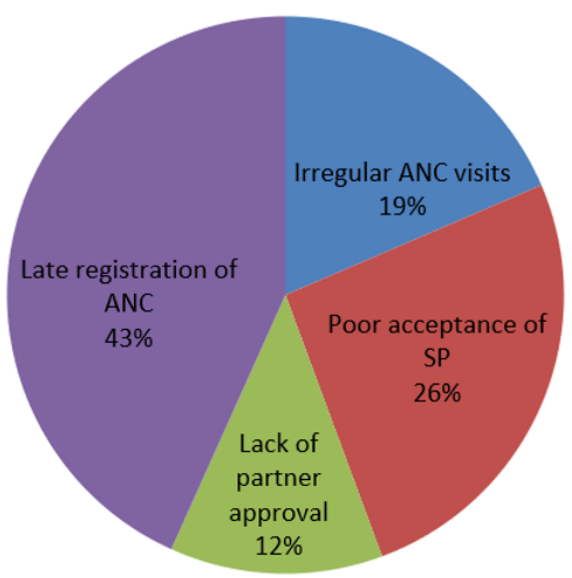

Figure 1: Patient factors.

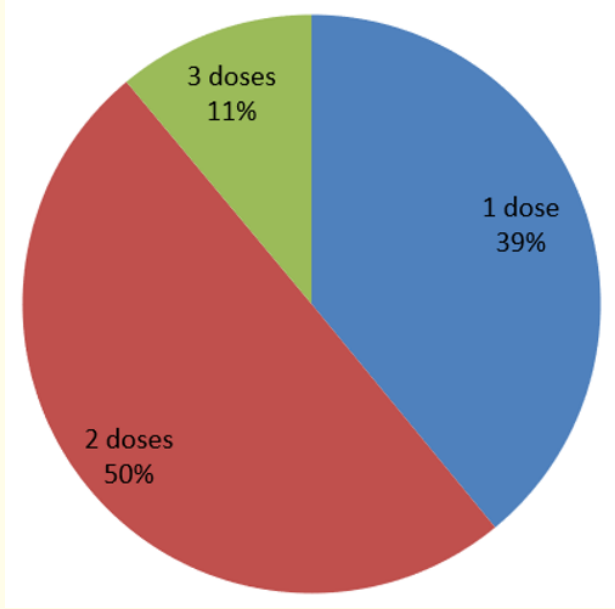

Figure 2: Proportion of Pregnant women who received SP.

\section{Discussion}

Socio - demographic factors of pregnant women's

Out of 461 interviewed pregnant women, 327(71.0\%) were in the age group of between 20 to 30 years, then $75(16.3 \%)$ of the respondents were in the age group of more than 30 years and 59(12.7\%) of the pregnant women were in the age group of less than 20 years. On the other hands, 448(97.2\%) of the four hundred and sixty one interviewed pregnant women were married, followed by $11(2.4 \%)$ of the respondents that were divorced and $2(0.4 \%)$ of the pregnant women were widowed. In terms of pregnant women occupations, more than half of them, 344(74.6\%) were unemployed, then less than a quarter, $75(16.3 \%$ ) of the respondents were able to do some trading, such as selling foods, cakes, drinks etc. and below less than a quarter $42(9.1 \%)$ of the interviewed pregnant women were civil servants. In 461 interviewed pregnant women, 258 (55.9\%) of them have been attending Islamiya schools, followed by 140 (30.4\%) respondents who have been attending secondary schools, then $57(12.4 \%)$ of the pregnant women attended primary schools and $6(1.3 \%)$ of the interviewed pregnant women attended tertiary schools respectively. On the issues of obstetric history, 235 (50.9\%) of these women were multigravidae and 387(83.9\%) were having 1- 5 parity. A total of one thousand four hundred and fifty living children and twenty - seven dead children were recorded during the interview. In this study, age status, education status and marital status of all the interviewed pregnant women as noted, were strongly associated ( $\mathrm{r}=1$ ) with uptake of SP (table 3 and 5).

These findings of the study are comparable to previous studies conducted in other areas, in rural Western Kenya, a study done by Ouma., et al. 2007, revealed that single and lower level of education as factors associated with the low IPTp coverage. Secondly, in Uganda, a study was carried out by Mbungu., et al. 2007, in Luwero district, which identified that lack of post primary education was

Citation: Bello Liman. “Factors Associated with Under Utilization of Intermittent Preventive Treatment Using Sulfadoxine - Pyrimethamine among Pregnant Women Attending Antenatal Clinic in Gusau District of Gusau Local Government Area, Zamfara State of Nigeria". Acta Scientific Nutritional Health 3.11 (2019): 36-52. 
associated with none use of at least one dose of IPTp -SP\{(odds Ratio $2.2,95 \% \operatorname{cl}(1.4-3.3)\}$.

On the contrary, in Tanzania, a study was conducted by Marchant., et al. 2008, which showed no evidence of any individual factors being associated with second dose coverage of SP, apart from the urban area. Age status, marital status, and education status of the pregnant women was not associated with second dose coverage of SP.

Factors Responsible for Low Utilization of sulfadoxine Pyrimethamine among pregnant women attending Antenatal clinic

Health system factors

In this study, the health system factors identified as responsible for low utilization of Sulfadoxine Pyrimethamine among the interviewed pregnant women attending antenatal clinic includes:

- Poor attitudes of health care providers

- $\quad$ Lack of IPTp training

- $\quad$ Lack of IPTp supervision

- Distance of health facilities from the community

- $\quad$ Lack of implementing DOT

- Poor attitudes of health care providers

In 461 of interviewed pregnant women, 100(21.6\%) of them were maltreated by the health care providers working at the antenatal clinic of seven selected health facilities. Some of the respondents complained bitterly that the antenatal clinic health care providers were sometimes shouting over them when they were seeking for more clarification of issues related to ANC services rendered to them and some respondents said the antenatal clinic health care providers were delaying them unnecessary by attending those who came after them first and according to them it was wrong and so discouraging to come to a health facility as early as possible for the ANC. (table 4).

This finding is comparable to previous studies conducted in Ghana, which stated that the Poor attitudes of health care providers were observed as part of the operational challenges in delivering the IPTp (Dufie, 2010 cited Hill and Kazembe, 2006), and another study stated that poor attitudes of health care providers, especially to late comers pregnant women; contributed to low IPT2 and IPT3 in Ghana (Dufie, 2010 cited PMI, 2007).

Contrary to this research findings, a research carried out in Ghana in Ejisu Juabeng district, by Smith., et al. 2010, identified the attitudes of health care providers as one of the factors that influence the uptake of SP. Similarly, a study was conducted in Ghana, at Bosomtwe district, by Dufie, 2010, which stated that, the attitude of health care providers served as a positive factor in the uptake of SP among the pregnant women.

This finding of the study could be as a result of the fact that, the monitoring and supervision on IPTp were not carried out in the antenatal clinic of primary health care centers and secondary health facility respectively, lack of training on interpersonal communication for health care providers of antenatal clinics and ignorance of antenatal clinics staffs on professional ethics.

\section{Lack of IPTp training}

In this study, seven (7) heads of ANCs were interviewed and only $1(14.3 \%)$ of them was able to train on IPTp. Out of five primary health care centers studied, the health care providers of the antenatal clinics of these facilities were not opportune to be trained on IPTp for some years. Some health care providers said they were only trained on LSS and IMCI some years back. For tertiary health facility, the antenatal clinic staffs were trained/ retrained on IPTp periodically with a view to build their capacity on IPTp for correct treatment of pregnant women during ANC. On the other hands, it was observed that the antenatal clinic staffs of secondary health facility studied were not able to undergo training on IPTp for so long period (table 4).

This study finding is comparable to previous work done in other areas, in Kampala, only $16 \%$ of the staff trained within the last six months (Dufie, 2010 cited Nankwanga and Gorettee, 2008). Similarly, a study conducted in rural western of Kenya, coverage of IPT increased after the trained of health care providers on IPTp (Dufie, 2010 cited Ouma., et al. 2005).

Contrary to finding from other studies, Steketee., et al. 2006, stated that Zambia recorded high coverage of IPTp second dose and sustained in the health system as a result of training and supervision of health care providers working at the antenatal clinic on IPTp. 
In a situation where the health care providers working at the antenatal clinic are not trained on IPTp, the pregnant women may be more likely to be treated wrongly. The regular training of health care providers on IPTp may help them to acquire all the necessary knowledge and skills required so as to enable them discharge their duties successfully. In addition, they may also refresh their ideas on the recent significant of the IPTp and policy.

This finding could be as a result of the fact that the training on IPTp may not be in the annual operational plan, therefore zero budgets allocated for IPTp training.

\section{Lack of IPTp supervision}

Similarly, seven (7) heads of ANCs were interviewed and only 1 $(14.3 \%)$ of them was able to experienced IPTp supportive supervision. Among the five primary health care centres studied, none of the antenatal clinic staffs were supervised on IPTp. The health workers said nothing like supervision on IPTp but the Zamfara state ministry of health in collaboration with an NGO called MAPS used to conduct what is called integrated supportive supervision quarterly in previous years, but last fourth quarter of 2014 and first and second quarters of the year 2015, no integrated supportive supervision conducted. In addition, in all the health facilities the supervisory itinerary was not seen talk less of displaying it on the wall (table 4). Usually supervision is carried out to ensure that the resources in terms of logistics and staffs required for successful implementation of IPTp program at the health facility level. Any deficiencies observed should be addressed as soon as possible.

Contrary to finding from other studies, Steketee., et al. 2006, stated that Zambia recorded high coverage of IPTp second dose and sustained in the health system as a result of supervision and training of health care providers working at the antenatal clinic on IPTp.

The finding of the study could be as a result of the fact that the human and material resources were inadequate, especially in primary health care centers and lack of budgetary allocation.

\section{Distance of health facilities from the community}

In 461 pregnant women interviewed, 250 (54.2\%) of them were living far away from the health facility. For these issues, the respondents complained on having some difficulties of transpor- tation from home to the health facility. The majority of the interviewed pregnant women said they used to pay three hundred Naira or more for to and fro, especially those who are attending tertiary and secondary health facilities for their ANC visits. While some of the interviewed pregnant women said they used to pay two hundred Naira or more as a transport fee per ANC visit. So as a result of these, some of the pregnant women faced difficulties to make ANC visit, early ANC visit and even completing four ANC visits as scheduled (table 4).

This finding of the study could be as a result of the fact that the health facilities were sited not closer to the community and low socioeconomic status of the family as well as population increased contributed to the pool positively.

\section{Lack of implementing DOT strategy}

In 7 health facilities so far studied, 3 (42.8\%) of them were successfully implemented directly observed therapy/treatment (DOT) to their clients during ANC. Three primary health care facilities out of five selected primary health care facilities studied were able to implement DOT at ANC and enhancing the compliance of DOT through provision of portable drinking water to pregnant women (Table 4). The two remaining health facilities studied, that is, tertiary and secondary health facilities, despite were having a large turn up of clients during ANC visits were not able to implement directly observed treatment (DOT) (table 4).

The finding of this study is comparable to previous work done in other areas, a study carried out in Tanzania, stated that DOT was not practiced $[8,9]$, a study also in Tanzania, revealed that $90.0 \%$ of interviewing pregnant women who received SP during ANC visits did not administer the tablets at the health facility, because of empty stomachs and sharing of water cups [6], similarly, a study carried out by Mubyazi., et al. 2005, revealed that only 34.4\% of pregnant women studied were able to administer SP under DOT.

So far, in line with the WHO recommendation, measurement of IPT is based on the number of SP doses being taken by pregnant mothers under the supervision of skilled health care providers. So, taken SP without the supervision of skilled health care provider is countless. 
The main reasons for having this finding of the study could be as a result of the fact that, the health facilities were administering SP against the DOT administration act, failure of the health facilities to provide potable drinking water to pregnant women during ANC or to direct the clients to ensure they provide potable drinking water during ANC visit for the purpose of directly observed therapy (DOT) strategy and lack of supervision.

\section{Patient factors}

\section{Irregular ANC visits}

Among the 461of pregnant women interviewed, 88(19\%) of them as observed were not able to visit the health facility for ANC purposes as scheduled. Some of the main reasons given by the pregnant women include location or distance of the health facility was far away from them, low socioeconomic status and poor attitudes of some health care providers working at the antenatal clinic (figure 1).

This study finding is similar to other studies carried out in some areas, a study conducted by Ritah in Rufiji district of Tanzania, 2012, which stated that irregular attendance of ANCs was among the factors that causing poor uptake of sulfadoxine - Pyrimethamine. In addition, a study carried out in Uganda, 2010, stated that late and irregular attendance of ANCs are causing the obstacles to antenatal schedules for the implementation of IPT - SP as directed [8].

The finding of this study could be as a result of the fact that, the attitude of the antenatal clinic health workers was below expectation, financial crisis within the family and distance of the health facilities from the communities as well as mistimed of pregnancy.

\section{Poor acceptance of SP}

Out of 461 pregnant women interviewed, $120(26 \%)$ of them were noted not having interest to swallow SP tablets due to some reasons stated as follows: The major reasons given by the respondents include not willing to swallow any form of tablets as medicine. So, instead of tablets form they preferred to use the syrup form because taking tablets drugs medicine may make them uncomfortable and even some time make them vomit. Secondly, some of the respondents have the fear of SP side effects, such as diarrhea, rashes, nausea etc. Similarly, other perception was the issue of abortion as a result of taking SP tablets. So, according to them, they preferred not to swallow SP during their pregnancy period (figure 1).

The finding of this study is similar to other studies carried out such as, a study carried out in Tanzania, which stated that the majority of the pregnant women linked low compliance with the IPTp to poor acceptance of SP, because of the perceived association of SP with side effects $[8,9]$, from the study also it was reported that the pregnant women threw away the SP after leaving the health facility, because of their belief and fear of the Steven - Johnson Syndrome (burning of the skin). A study conducted in Korogwe district, North -East Tanzania, by Mubyazi., et al. 2005 stated strongly changed due to fear of Sulfadoxine Pyrimethamine harmful effects to pregnant women and the foetus.

Some pregnant women believed that taking SP during pregnancy could possibly cause abortion, which was why they have made their minds to administer less recommended dosage. A study conducted by Gimnig., et al. 2006, revealed rare allergic reaction of SP to studied pregnant women. Similarly, a study by FDA, 2007, Ouma., et al. 2006 stated that if the reactions occurred, the drug must be withdrawn.

The main reasons for having this finding could be as a result of women's attitude towards the drugs, SP induced side effects, such as Steven Johnson syndrome (burning of the skin), rashes, nausea, diarrhea etc. and inadequate awareness of the importance of SP against malaria in pregnancy.

\section{Late registration of ANC}

It was observed that out of 461 of interviewing pregnant women, $198(43 \%)$ of the respondents were making first visit to a health facility for ANC when the pregnancy was between four to six months respectively. The reasons behind these were given by the interviewing pregnant women as follows: low socioeconomic status, distance of the health facility, lack of guidance for ANC visits and delay of husband's permission (figure 1).

This finding is comparable to a study carried out in Uganda, 2010, which revealed that late and irregular attendance to ANCs disrupt antenatal schedules for proper delivery of IPT [7] (Francis, 2012 cited Ndyomugyenyi., et al. 2010). 
The reasons for having $43 \%$ of interviewed pregnant women who were not making early registration of ANC in this study, could be as a result of inadequate awareness of gestation age, low socio - economic status and delay of early husband permission as well as ignorance of malaria in pregnancy menace to mother, baby or both of them.

\section{Lack of partner approval}

In 461 of pregnant women interviewed, 55(12\%) of them complained of having serious difficulties to seek permission to visit a health facility for ANC during pregnancy period. Still on the responses of the pregnant women, some of them said coming to ANC when pregnant was depending on the luck of the pregnancy. This group of pregnant women then continues saying that coming to a health facility for ANC was very rare as a result of not having the support and courage from their husbands. According to them most of the time their husbands allowed them to visit the health facility for ANC only if something was noted not in order with pregnancy. So, situation like this, may positively contribute in the area of low utilization of SP among the pregnant women attending ANC (figure 1).

This finding is comparable to a study carried out in Uganda, 2010, which revealed that late and irregular attendance to ANCs disrupt antenatal schedules for proper delivery of IPT (Francis, 2012 cited Ndyomugyenyi., et al. 2010).

This finding could be as a result of the fact that the husbands were not aware with the menace of malaria in pregnancy, low socio - economic status and inadequate caring of pregnant women by their husbands.

\section{Focus group discussion}

Most of the pregnant women during discussion explained that the only way of getting SP tablets was during ANC visits at the health facility. In the discussion they said the first dose of SP was ideally administered at the fourth months of pregnancy, while the other subsequent doses were issued monthly until when the pregnant women delivered.

For pregnant women's attitude, some of them said they preferred to administer SP syrup rather than tablets. Some reasons given included stomach upset, vomiting, discomfort etc. Based on this, few among them said that they threw away the tablets when they were at home.

For pregnant women's perception, the majority of the participants believed that SP tablets were given to them as a prevention measure against malaria. Secondly, they said ideally each pregnant woman was expected to administer at least three doses of SP before delivery. Some of the challenges narrated included inadequate information about the ANC visits, lack of permanent permission from their husbands, side effects of the drug and distance of the health facility. Others are poor attitude of some ANC health care workers, lack of potable water within the health facility premises and long ANC queue during the ANC session.

Assessment of knowledge level on SP among the pregnant women attending antenatal clinic

The knowledge level of pregnant women was analyzed based on the outcomes of interviews and focus group discussions during data collection. Out of 461 interviewed pregnant women, $310(67.2 \%)$ of the pregnant women were able to knew how to protect themselves against malaria during the pregnancy. Similarly, $263(57 \%)$ of the interviewed pregnant women knew when to start taking SP and 300 (65\%) of the pregnant women interviewed also known when to stop taking SP. On the other hands, 204 (44.2\%) of the pregnant women interviewed, knew the effects of malaria to mother, baby or both of them. It was also noted that, 101(21.9\%) of the interviewed pregnant women were able to knew how to use SP for prevention of malaria in pregnancy. Still among the interviewed pregnant women, $72(15.6 \%)$ of them were able to be aware with the side effects of SP, then $438(95 \%)$ of the respondents were also known the amount of SP tablets needed at four months of pregnancy and 446(96.7\%) of the interviewed pregnant women as analyzed got awareness about SP through health education talk held at the health facility during ANC visits (table 6).

These findings obtained are compared to previous work done in other areas, in East Africa, 90\% of interviewed pregnant women knew that SP was the drug recommended for IPT and $77.2 \%$ of pregnant women interviewed also had the perception that IPT with SP has a role of health benefits to them and their babies [5].

Contrary to these findings from other studies, in Kampala, 21\% of the interviewed pregnant mothers knew how to go in protect- 
ing themselves against malaria by use of SP, $31.5 \%$ of the pregnant women interviewed were aware that SP has been recommended for prevention of malaria in pregnancy and only $4.5 \%$ of the pregnant women knew the recommended doses of SP to be administered. More than $95 \%$ of the interviewed pregnant women said that no health education on IPT provided to them during ANC sessions. The knowledge level of pregnant women on the effects of malaria to pregnant mothers and their babies was poor as observed in two health facilities located in Edo state of Nigeria [5] and $70.0 \%$ of the interviewed pregnant women did not know the timing of IPT administration and this likely caused the incomplete administration of SP [5].

This finding as noted could be as a result of the fact that the interviewed pregnant women understood the health education talks delivered by antenatal clinic staff during ANC visits.

\section{Proportion of Pregnant women who received SP}

In 461of interviewed pregnant women, more than a quarter, 180 (39\%) of them administered first dose of SP and half of them, $231(50 \%)$ had received second doses of SP respectively. For the third doses, less than half of the quarter, 51(11\%) of the interviewed pregnant women got third doses of SP (figure 2).

This finding is comparable to a study carried out in Tanzania, by Mubyazi., et al. 2008; the study revealed that 2/3 of the pregnant women studied administered two doses of SP.

Contrary to this study, a quarter of $1 / 3$ of the pregnant women studied administered 2 doses of SP (Mohammad, 2013 cited Akinleye., et al. 2009). Studies that are contrary to this study also include, $95 \%$ of the SP first dose, $77 \%$ of SP second doses and $44 \%$ of SP third doses, respectively (Bosomtwe, 2010), 9.7\% of the SP first dose, $6.6 \%$ of SP second doses and $2 \%$ of SP doses of third doses in Zamfara State of Nigeria [1] and 43\% of the SP first dose and $21.4 \%$ of second doses in Rufiji district, southern Tanzania (Ritah, 2012). Tanzania HIV - AIDS and Malaria Indicator Survey (THMIS) reported that $30 \%$ of pregnant women in Tanzania mainland administered two or more doses of IPTp at ANC visits (Francis, 2012 cited Eijk., et al. 2011, Gutmana., et al. 2011, Mboera., et al. 2007).

In support of taken more than 2 doses, the findings of some studies revealed that, two doses of SP may have little effect on maternal Parasitaemia on delivery [6] and the second study stated that, in seasonal transmission settings more than 2 doses may be required to prevent placental re- infection [6]. Sulfadoxine Pyrimethamine administration in the second and third trimesters showed safety and effectiveness in terms of protection for peripheral and placental malaria, maternal malaria in pregnancy and as well as minimizing the risk of low birth weight (Francis, 2012 cited WHO, 2006). For prevention control of malaria in pregnancy, especially in malaria endemic area, WHO recommended administration of two to three doses of SP for IPT (Francis, 2012 cited Crawley, 2007, WHO, 2008).

The finding of this study could be as a result of the fact that the SP tablets were given free of charge to all eligible pregnant women in all the selected facilities, availability of SP in the facilities and effective health education talks during ANC session.

The Availability of SP in Primary, Secondary and Tertiary Health facilities

The research study conducted has shown that, all the seven (7) studied health facilities (100\%) had enough quantities of SP at their stores for distribution free of charge to clients during ANC visits. From the observation made so far, it was noted that the health facilities did not experience either stock out or shortages of SP tablets during the distribution periods. The health facilities usually received their SP allocations quarterly based on consumption rate of each facility (table 7).

The findings of this study are comparable to previous research work conducted in other places, $94.1 \%$ of the health facilities provided IPTp did not experience stock out of SP in the last six months in Ghana (Dufie, 2010 cited PMI survey, 2008).

Contrary to findings from other studies, $27 \%$ of health facilities experienced stock out of SP in the last six months in Ghana [5], $40 \%$ of the interviewed pregnant women had never received SP due to non-availability of SP in the facilities, in Tanzania [5] and a study carried out revealed that third of the pregnant women did not receive SP for IPTp due to unavailability of the commodity in the health facilities [6]. Therefore, SP stock out may likely to cause a major barrier to the successful implementation of IPTp in any nation, Nigeria inclusive. 
This finding could be because of the fact that the quarterly allocation of SP of all the selected health facilities was done by the nongovernmental organization called MAPS, currently working in the State. Secondly, the quarterly allocation of SP of health facilities was based on a consumption rate formula.

Health care provider's knowledge level on the use of SP

In this successful conducted study, all the 7(100\%) interviewed health care providers knew what IPTp means all about. Similarly, $5(71.4 \%)$ of them believed that the Fansidar was recommended as the first line anti-malarial drug to pregnant women in Nigeria and also $5(71.4 \%)$ of the interviewed health care providers knew that a health facility with infrastructures to determine gestational age can start IPTp after quickening or 13 weeks of pregnancy. In case of DOT strategy, all the health care providers interviewed, $7(100 \%)$ were aware that DOT strategy was simply means administration of anti-malarial medicine under the close supervision of skilled health care providers. Similarly, all the interviewed health care providers, $7(100 \%)$ were aware that vomiting, headache, rashes and nausea are the side effects of SP, then $5(71.4 \%)$ of the interviewed health care providers were warmly agreed that HIV pregnant women placed on cotrimoxazole chemoprophylaxis are not eligible to swallow SP and also 5(71.4\%) of them have agreed that pregnant women those were allergic to sulpha drugs are not eligible to swallow SP tablets (table 8).

The findings of the study are comparable to a study carried out in Gambia, which revealed that pregnant women relied on health care providers to provide a safe drug to them at the right time [5].

This finding of the study could be as a result of the fact that, the interviewed health care providers were so far having the knowledge, experience and relevant qualification related to their job [1025].

\section{Conclusion}

In this particular study, the factors identified as responsible for low utilization of Sulfadoxine Pyrimethamine among the pregnant women attending an antenatal clinic in Gusau district, required serious attention from all levels (federal, state, LGA, health facility and community) in order to promote the uptake of SP, so as to minimize the menace of malaria in pregnancy that may likely lead to the reduction of maternal and infant mortality.
Federal level

- Ensure dissemination of guidelines on malaria in pregnancy.

- $\quad$ Availability of framework for implementation of malaria in pregnancy guidelines.

- Set up coordination mechanism for IPTp implementation

- $\quad$ Provide Behavioral Change Communication strategy and guidelines for IPTp to Zamfara State and LGAs.

- Provide technical support on IPTp implementation to Zamfara State

- Provide SP in form of syrup as second alternative

- Ensure monitoring, supportive supervision and evaluation of IPTp implementation.

State level

- Ensure the implementation of malaria in pregnancy interventions

- Train/retrain of health care providers working at ANC on IPTp and IPC

- $\quad$ Take the lead for availability of SP in public health facilities and ensure sustainability

- Provide technical support on IPTp implementation to LGAs

- Support for accurate documentation and data management

- $\quad$ Set - up appropriate feedback mechanism to LGAs

- Disseminate guidelines on IPTp to all relevant stakeholders

- Ensure monitoring, supervision and evaluation of IPT implementation.

Local government area level

- $\quad$ Promote IPTp uptake through all possible means

- $\quad$ Procure and distribute SP to all ANC health facilities

- Provide a system that will encourage ANC attendance

- $\quad$ Provide technical Support to health facilities for IPTp implementation

- Ensure supportive supervision on ANC services

- $\quad$ Set -up appropriate feedback mechanism to health facilities

- Establish a community based awareness approach on IPTp.

- Monitor and evaluate IPTp activities from time to time. 


\section{Health facility level}

- $\quad$ Administer SP as DOT at ANC and provide clean potable drinking water for the purpose.

- $\quad$ Conduct regular follow up

- $\quad$ Provide on the job training on IPTp

- Involve community of the facility catchment areas when planning for ANC session

- $\quad$ Promote IPTp uptake through all possible means

- $\quad$ Set -up appropriate feedback mechanism to community.

Community level

- Create awareness on the usefulness of ANC and risk of malaria during pregnancy

- $\quad$ Conduct home visits to encourage pregnant women for early registration of ANC as well As regular ANC visits

- $\quad$ Ensure prompt referral of pregnant women to health facility

- $\quad$ Ensure the use of malaria messages during home visits.

\section{Bibliography}

1. National Population Commission. Nigeria Demographic and Health Survey. Report summarises the findings of the 2013. National Population Commission and ICF International (2013).

2. Federal Ministry of Health. "National Guidelines and Strategies for Malaria prevention and Control during Pregnancy". Abuja. ABJ: FMOH (2014).

3. Path. "Community - based approaches to Intermittent Preventive Treatment of Malaria in Pregnancy". A review of recent studies (2014).

4. Guyatt H L., et al. "Use of intermittent preventive treatment and insecticide treated bed nets by pregnant women in four Kenyan districts". Tropical Medicine and International Health 9 (2004): 255-261.

5. Gifty Dufie ANTWI. "Factors influencing the uptake of intermittent preventive treatment of malaria in pregnancy in the Bosomtwe district of Ghana". M. SC Thesis, School of Medical Sciences, Kumasi, Ghana (2010).
6. Kakonkanya - Kambole Namunji Gertrude. "Effectiveness of intermittent preventive treatment of full course of Sulphadoxine Pyrimethamine in clearance of placental malaria parasites in pregnancy in Kafue district of Zambia". MPH Thesis, University of Zambia (2010).

7. State Ministry of Health. Zamfara State Annual Operational Plan for Malaria. Gusau. GUS: Ministry of Health. State Ministry of Health (2015). Zamfara Annual Operational Plan for Malaria Elimination. Gusau. GUS: Ministry of Health (2013).

8. Francois., et al. "Intermittent presumptive treatment in pregnancy with Sulfadoxine - Pyrimethamine: a counter perspective". Malaria Journal 14 (2015): 248.

9. Mubyazi G., et al. "Intermittent preventive treatment of malaria during pregnancy. A qualitative study of knowledge, attitudes and practices of district health managers, antenatal care staff and pregnant women in Korogwe district, North- East Tanzania”. Malaria Journal 4 (2005): 31.

10. Cox - Sigh J., et al. "Plasmodium Knowlesi malaria in human is widely distributed and potentially life threatening". Clinical Infectious Diseases 46 (2008): 165-171.

11. Charles 00., et al. "Intermittent use of Sulfadoxine - Pyrimethamine for Malaria Prevention: a cross sectional study of knowledge and practices among Ugandan women attending an urban antenatal clinic". Malaria Journal 13 (2014): 399.

12. Dr Taofeek Ibrahim. Research Methodology and Dissertation Writing for Health \& Allied health Professionals. Sokoto. SK: Dept. of Community Medicine, University (2010).

13. Feng G., et al. "Decreasing burden of malaria in pregnancy in Malawian women and its relationship to use of intermittent preventive therapy or bed nets". Plos One 5 (2010): e12012.

14. Gamble C., et al. "Insecticide treated nets for preventing malaria in pregnancy”. Cochrane Database System Review CD (2006).

15. Holtz TH., et al. "Use of antenatal care services and intermittent preventive treatment for malaria among pregnant women in Blantyre District, Malawi". Tropical Medicine and International Health 9 (2004): 77-82. 
16. Murtala M. "Impact analysis of intermittent preventive treatment with sulfadoxine Pyrimethamine among pregnant women attending antenatal clinic of Kotorkoshi district Bungudu LGA, Zamfara State of Nigeria". MPH Thesis, Bamenda International University, Cameroon (2013).

17. National Primary Health Care Development Agency. "National Guidelines for Development of Primary Health Care System in Nigeria". Damnori: Nigeria (2012): 192-196

18. Ogbodo S 0., et al. "Malaria Parasitaemia among pregnant women in a rural community of eastern Nigeria" (2009).

19. Puthuchira Ravi., et al. "Does Socio - demographic factors influence women's choice of place of delivery in rural areas of Tamilnadu State in India". American Journal of Public Health Research 2 (2014).

20. Ritah Francis Mutagonda. "A study of pregnant women and Health workers knowledge on malaria prevention and treatment guidelines during pregnancy". M. SC Thesis, Muhimbili University of Health and Allied Sciences, Tanzania (2012).

21. Steketee RW., et al. "The burden of malaria pregnancy in malaria endemic areas". The American Journal of Tropical Medicine and Hygiene 64 (2004): 28-35.

22. UK essays. Intermittent preventive treatment of malaria in pregnancy Africa (2014).

23. Van Eijk AM., et al. "Use of antenatal Services and delivery Care among Women in Rural western Kenya a community based survey". Reproductive Health 32 (2006).
24. Vudriko P. "Quality of Sulfadoxine - Pyrimethamine (SP) Tablets Sold in Drug Outlets in Arua District - Uganda" M.SC Thesis, Makerere University, Uganda (2010).

25. WHO Evidence Review Group. Intermittent preventive treatment of malaria in pregnancy (IPTp) with Sulfadoxine - Pyrimethamine (SP). Meeting report, WHO headquarters, Geneva (2012).

\section{Volume 3 Issue 11 November 2019} (C) All rights are reserved by Bello Liman. 